\title{
Modelling resin production distributions for Pinus Pinaster Ait using two probability functions
}

\author{
Nikos Nanos ${ }^{\mathrm{a},}{ }^{*}$, Wubalem Tadesse ${ }^{\mathrm{a}}$, Gregorio Montero ${ }^{\mathrm{a}}$, Luis Gil ${ }^{\mathrm{b}}$ and Ricardo Alia ${ }^{\mathrm{a}}$ \\ ${ }^{a}$ Centro de Investigacion Forestal, CIFOR-INIA, Apdo 8111, 28080 Madrid, Spain \\ ${ }^{\mathrm{b}}$ Unit of Physiology and Genetics, ETSI Montes, 28040 Madrid, Spain
}

(Received 12 April 1999; accepted 10 February 2000)

\begin{abstract}
The Weibull and the Chaudhry-Ahmad probability density functions were used to model resin production distributions for maritime pine stands. Maximum likelihood was used for parameter estimation. Data were collected during one season in two sets of plots. Set 1 consisted of two 50-tree and one 100-tree plots. Bootstrap re-sampling showed that the Weibull parameters had smaller estimation errors for small sample sizes. Set 2 consisted of thirty-seven 10-tree plots. No significant differences in the fit of the density functions were detected. Parameters of both models were found to be well correlated with the mean plot production as well as with the within plot coefficient of variation. The results did not reveal any major differences between the Weibull and the ChaudhryAhmad probability functions. The most appropriate model should be chosen at later stages when parameters of both functions are regressed against easily measured stand attributes.
\end{abstract}

resin production distribution / Pinus pinaster / Weibull / Chaudhry and Ahmad / modelling

Résumé - Modélisation de la distribution de production de résine pour Pinus pinaster Ait au moyen de deux lois de probabilité. La distribution de la production de résine de peuplements de pin maritime est modélisée par les fonctions de densité de probabilité de Weibull et de Chaudhry-Ahmad La méthode du maximum de vraisemblance est utilisée pour l'estimation des paramètres. Les données ont été mesurées dans deux groupes de placettes pendant une saison de récolte. Pour le premier groupe qui est composé de deux placettes de 50 arbres et d'une autre de 100 arbres, le re-échantillonnage «bootstrap» a montré que les paramètres de la fonction de Weibull ont une erreur plus faible pour les petits échantillons que celle de la fonction de Chaudhry-Ahmad. Le second groupe est constitué de 37 placettes de 10 arbres. Aucune différence significative entre l'ajustement des deux fonctions de probabilité n'est mise en évidence. Les paramètres des deux modèles sont corrélés avec les productions moyennes des placettes et avec les coefficients de variation intra-placettes. Les résultats ne montrent pas de différences significatives entre les fonctions de probabilité de Weibull et de Chaudry-Ahmad. Le modèle définitif sera choisi ultérieurement après la mise en relation entre les paramètres des deux fonctions et des variables dendrométriques facilement mesurables.

distribution de la production de résine / Pinus pinaster / Weibull / Chaudhry et Ahmad / modélisation

\section{INTRODUCTION}

Resin tapping was an important rural activity in the Mediterranean basin until the 1970s when the international crisis in natural resin prices rendered this traditional labor no longer profitable. Presently Pinus pinaster Ait (maritime pine) is the only species tapped in Spain. Resin tapping is restricted to a few areas (mainly Central Spain), where trees produce a sufficient quantity of resin and extraction is facilitated by favorable terrain. Recently, an increased demand for natural resins has pushed up prices and many of the abandoned stands are tapped again.

* Correspondence and reprints

Tel. 349134768 15; Fax. 349135731 07; e-mail: nanos@inia.es 
Scientific interest in this forest product has traditionally been focused on improving the extraction method and producing improved genetic material since it was noted early that resin production is under high genetic control [15].

Despite long-standing scientific interest, there is a lack of information about the silvicultural treatment that should be applied to stands dedicated to resin production and no prediction models exist that can help forest managers determine whether tapping a certain stand will be profitable or not. Moreover, if a resin production model can be combined with a growth and yield model, then the decision will be made even more easily.

The first step of the modelling process is to determine the probability density functions (pdf) that can model the stand production distribution. To our knowledge no studies have been made on this topic.

Bailey and Dell [2] introduced the well-known Weibull function in the forestry field in their effort to model the diameter distributions of pure, even-aged stands. This function has received a great deal of attention due to its flexibility and simplicity [11-14, 20]. Apart from diameter distribution model, it has been used to model tree-age distributions [4], vertical distributions of foliage weight and surface area [3] as well as seed cone survivorship curves [6].

Chaudhry and Ahmad [5] presented the second pdf used in this study. They derived their function as a solution to a generalized Pearson differential equation. The properties, parameter estimation and applications of the function are discussed in the same paper so no further details will be presented here. This function was chosen among many other candidates because of its bi-parametric nature and flexibility.

In the present study, the Weibull and the ChaudhryAhmad probability functions have been used to model resin-yield distributions. Accuracy of model predictions was assessed with bootstrap re-sampling and an error index developed for this case. These probability density functions could be used in future to construct models of stand resin production.

\section{MATERIALS AND METHODS}

\subsection{Study area}

The experiment took place in pure, even-aged stands of Pinus pinaster located in central Spain. The study area is characterized by the complete absence of significant slopes. The soil texture is relatively uniform, with a high percentage of sand (always over the 90\%) and low content of organic matter [1], which makes the area rather unproductive. The climate is typical Mediterranean with $460 \mathrm{~mm}$ of mean annual precipitation and $11.3^{\circ} \mathrm{C}$ of mean annual temperature.

\subsection{Data}

Data came from a total of 40 experimental plots. Two sets of plots were installed according to their main objective. The first set of plots was used to select the most appropriate among various probability functions and to assess the precision of pdf 's parameter estimates. Three plots were established, two of them including 50 trees (Co1-C1) and one 100 trees per plot (S1). The second set was used to validate the previously chosen probability functions at a broad range of environmental and silvicultural conditions. It included thirty-seven 10-tree plots. Location of plots is found in figure 1 .

Trees in each plot were numbered and tapping was carried out using bark chipping with application of acid paste, following the same protocol for all the trees. The resin produced by each individual was weighed in the field by visiting plots every 20 to 30 days (when pots were full of resin). Pots were weighed full and empty, and the net resin weight was computed by subtracting the two measures. The tapping period lasted six months, from May to October 1998.

\subsection{Statistical analysis}

The bi-parametric Weibull function is given by:

$$
f(x)=c / b(x / b)^{(c-1)} \exp \left(-(x / b)^{c}\right)
$$

where $x$ is the tree resin production $(\mathrm{kg})$ and " $b$ " and " $c$ " the scale and shape parameter respectively.

The Chaudhry and Ahmad probability function for the random variable $x$ is given by:

$f(x)=2(a / \pi)^{1 / 2} \exp \left(2 a \mu_{0}^{2}\right) \exp \left(-a \mu_{0}^{2}\left(\left(x / \mu_{0}\right)^{2}+\left(\mu_{0} / x\right)^{2}\right)\right)$

where $x$ is the resin production $(\mathrm{kg})$, " $\mu_{0}$ " the location parameter of the distribution that coincides with the mode and " $a \mu_{0}{ }^{2}$ " the shape parameter [5].

There exists a large and growing literature on the estimation methods of the parameters of the Weibull function. Maximum likelihood (ML), percentile, and moments method have been widely used for parameter estimation. Shiver [20], using data from a simulator developed to provide slash pine diameter distributions, found that percentile estimators were biased but had smaller variance than ML estimators.

In the present study, maximum likelihood was used for parameter estimation. Regarding the Chaudhry-Ahmad 


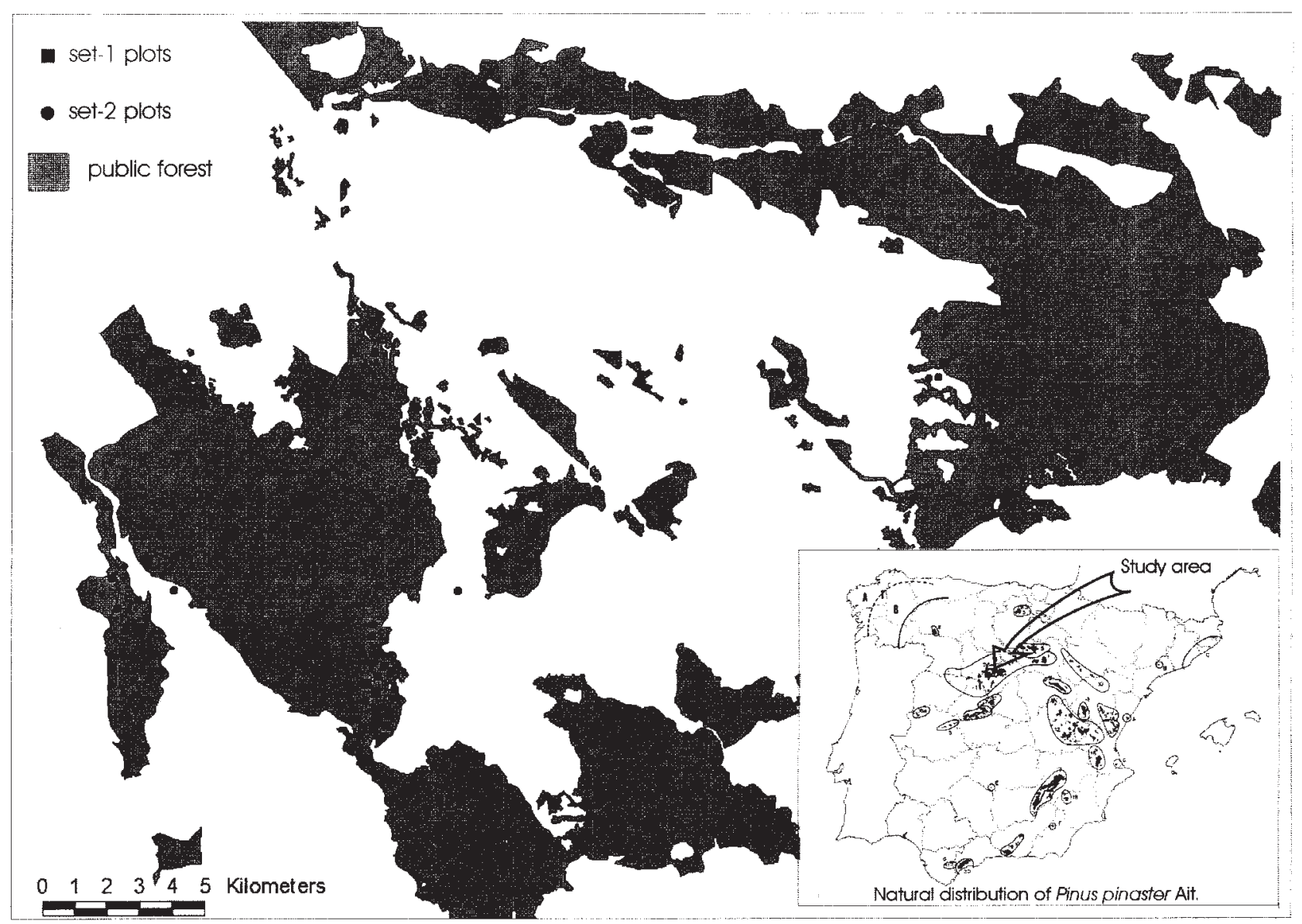

Figure 1. Installed plots.

pdf, the solution of the ML equations is straightforward [5], but for the Weibull likelihood, maximization is achieved iteratively. We used a Newton-Raphson ML estimation procedure for the Weibull parameters, written in SAS ${ }^{\circledR}(\mathrm{SAS} / \mathrm{IML})$.

\subsection{Set 1}

The chi-square test was used to check for the goodness-of-fit of the two probability functions for the set-1 plots. The null hypothesis to be tested is that $f(x, \vartheta)$ is the true distribution function ( $x$ being the vector of observations and $\vartheta$ the vector of parameters). Usually, $f(x, \vartheta)$ is not completely specified in the null hypothesis because its parameters have to be estimated from the data. In that case the user should regard $p$-values with caution [19]. When ML is used for parameter estimation, the asymptotic distribution of the $x^{2}$ statistic will be between the $x^{2}(a, k-1)$ and the $x^{2}(a, k-1-q)$, (" $q$ " being the number of parameters estimated from the data, " $k$ " the number of classes into which trees fall and " $a$ " the level of significance). We compared the test statistic to the chi-square distribution with both $k-1$ and $k-1-q$ degrees of freedom.

The Akaike's information criterion (AIC), has been also used to compare the fit of the two distributions. We first computed the log-likelihood ratio given by:

$$
\ln L(x)=\ln \left\{\frac{\prod_{i=1}^{n} f_{\mathrm{A}}\left(x_{i}, \vartheta_{\mathrm{A}}\right)}{\prod_{i=1}^{n} f_{W}\left(x_{i}, \vartheta_{\mathrm{W}}\right)}\right\}
$$

where $L(x)$ is the likelihood ratio, $f_{\mathrm{A}}$ and $f_{\mathrm{W}}$ are the Chaudhry-Ahmad and the Weibull density function, $x_{i}$ the vector of observations and $\vartheta_{\mathrm{A}}, \vartheta_{\mathrm{W}}$ the vectors of estimated parameters for the Chaudhry-Ahmad and the Weibull density respectively. 
Since the distributions to be compared have the same number of independent parameters, the Chaudrhy-Ahmad fits better than the Weibull when $\ln L(x)>0$ [19].

A bootstrap re-sampling technique [8], was also used to assess the absolute error in parameter estimates of the two probability functions. Re-sampling was restricted to the set -1 plots (S1, Co1 and $\mathrm{C} 1$ ) since the rest of the plots were not big enough. One thousand bootstrap samples of different size were randomly chosen from the three plots. The size of the samples (trees per sample) varied from 10 to 40 for the $\mathrm{Co} 1$ and $\mathrm{C} 1$ plots and from 10 to 90 for the S1 plot. A total of 15000 samples were constructed (4000 for each of the Co1 and C1 plots and 7000 for the S1 plot). Sampling was done by randomly selecting a tree from the sample and replacing it before the next tree was chosen. Parameters of both probability functions were calculated for each bootstrap sample and the average absolute error in parameter estimation for every sample size was computed. In order to compare the probability functions in terms of accuracy of parameter estimations, we computed the proportional absolute error $(P A E)$ for each bootstrap sample size:

$$
P A E_{i}=\frac{\left|p_{i}-p_{\mathrm{r}}\right|}{p_{\mathrm{r}}} 100
$$

where $i=10,20, \ldots, 90$ is the bootstrap sample size, $p_{i}$ is the average value of the parameter for 1000 bootstrap samples of size $i, p_{\mathrm{r}}$ is the value for the parameter in the original sample. This error index permits the comparison of the two probability functions in terms of accuracy of parameter estimation, since it provides the proportional estimation error.

\subsection{Set 2}

Reynolds et al. [19] report that when trying to select the best model to fit the observed distributions, one should consider the usefulness of the model from a practical point of view. In our case, an error of one tree at low production classes is less important than an error of one tree at higher classes. We therefore grouped the data into $1 \mathrm{~kg}$ classes and adopted the weighted sum of the absolute differences between observed and estimated frequencies, as an index of the accuracy of model estimations. Weights for each class were equal to the mean class production:

$$
E I=\sum_{i=1}^{n}\left(x_{i}\left|f_{\mathrm{o}_{\mathrm{i}}}-f_{\mathrm{p}_{\mathrm{i}}}\right|\right)
$$

where, $E I$ is the error index, $i=1,2 \ldots n$, the number of classes to which trees fall, $x_{\mathrm{i}}$ the mean of class $i, f_{\mathrm{oi}}$ and $f_{\mathrm{pi}}$ are, respectively, the observed and estimated frequencies of trees falling into class $i$.

The above mentioned error index has been computed for the set- 2 plots and for both models. A paired-samples t-test was then used to check for significant differences between model estimations.

\section{RESULTS}

\subsection{Set-1}

The observed distributions for the set-1 plots (figure 2) are indicative of differences among sites with respect to their resin yield capacity. In plot $\mathrm{C} 1,40 \%$ of the trees produce more than $4 \mathrm{~kg}$ of resin while the corresponding percentage is $0 \%$ and $12 \%$ for $\mathrm{C} 1$ and $\mathrm{S} 1$ plot respectively. Descriptive statistics as well as the parameter estimates for the set-1 plots are shown in table $I$.

No large difference exists between the two probability functions (figure 2) but the Chaudhry-Ahmad pdf is more skewed to high yield classes than the Weibull distribution.

\begin{tabular}{|c|c|c|c|c|c|c|c|c|c|}
\hline \multirow[b]{3}{*}{ Plot } & \multicolumn{5}{|c|}{ Descriptive Statistics } & \multicolumn{4}{|c|}{ Maximum Likelihood Parameter Estimates } \\
\hline & \multirow[b]{2}{*}{ Min } & \multirow[b]{2}{*}{ Max } & \multirow[b]{2}{*}{ Mean } & \multirow[b]{2}{*}{ Sk } & \multirow[b]{2}{*}{ Kur } & \multicolumn{2}{|c|}{ WEIBULL } & \multicolumn{2}{|c|}{ CHAUDHRY \& AHMAD } \\
\hline & & & & & & $c$ & $b$ & $a$ & $\mu_{0}$ \\
\hline S1 & 0.75 & 6.27 & 2.92 & 0.84 & 0.90 & 2.81 & 3.27 & 0.110 & 2.290 \\
\hline $\mathrm{C} 1$ & 0.90 & 8.75 & 3.73 & 0.69 & -0.21 & 2.05 & 4.22 & 0.040 & 2.370 \\
\hline Co1 & 0.35 & 3.93 & 1.75 & 0.39 & -0.32 & 2.25 & 1.97 & 0.180 & 1.000 \\
\hline
\end{tabular}

Table I. Descriptive statistics and parameter estimates for set-1 plots.

Min: minimum plot production; Max: Maximum plot production; Mean: average of the plot; Sk: Skewness(for the normal distribution Sk = 0); Kur: Kurtosis (for the normal distribution kur $=0$ ); $a, \mu_{0}, b, c$ : Maximum likelihood parameter estimates. 

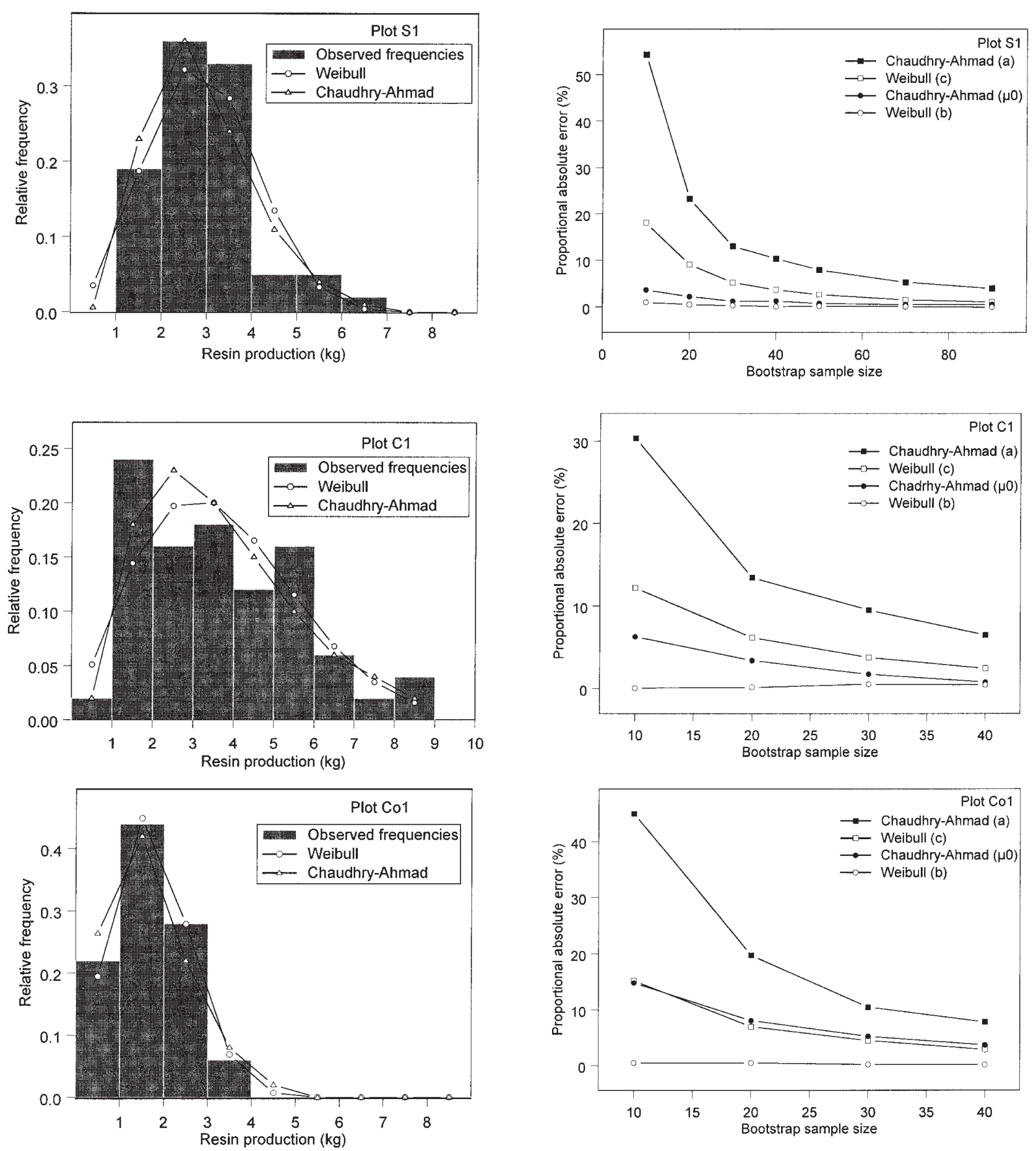

Figure 2. Observed frequencies and fitted models for set-1 plots.

Figure 3. Proportional absolute error in parameter estimates with respect to bootstrap sample size. 
Table II. Akaike's Information Criterion and chi-square test.

\begin{tabular}{|c|c|c|c|c|c|}
\hline \multirow[b]{3}{*}{ Plot } & \multirow[b]{3}{*}{ AIC } & \multicolumn{4}{|c|}{ CHI-SQUARE } \\
\hline & & \multicolumn{2}{|c|}{ Chi-square statistic } & \multicolumn{2}{|c|}{ Critical Values } \\
\hline & & WEIBULL & $\begin{array}{l}\text { CHAUDHRY } \\
\& \text { AHMAD }\end{array}$ & $x^{2}(a, k-1)$ & $x^{2}(a, k-1-q)$ \\
\hline S1 & 3.07 & 17.30 & 11.19 & 11.07 & 7.81 \\
\hline $\mathrm{C} 1$ & 1.92 & 7.73 & 5.39 & 15.50 & 12.59 \\
\hline Co1 & -1.69 & 0.21 & 1.45 & 7.81 & 3.84 \\
\hline
\end{tabular}

AIC: Akaike's Information Criterion; $x^{2}(a, k-1), x^{2}(a, k-1-q)$ : chisquare statistic for $a=0,05$ the level of significance, $k$ the number of classes into which trees fall and $q$ the number of estimated parameters.

The chi-square test showed that, at 0.05 significance level the null hypothesis is rejected in plot $\mathrm{S} 1$ for both the probability functions but it cannot be rejected for plots $\mathrm{C} 1$ and Co1 (table II). It should be noted that although the null hypothesis is rejected for the S1 plot, the ChaudrhyAhmad function fits better the distribution since its chisquare value is much smaller than that of the Weibull.

The AIC leads to the conclusion that the fit of the Chaudhry-Ahmad density function is better in plots S1 and $\mathrm{C} 1$ but worse in plot $\mathrm{Co} 1$ (table II).

The results of 1000 bootstrap samples of different sizes are presented in figure 3. The "a" parameter of the Chaudhry-Ahmad function has bigger $P A E$ for all plots and all sample sizes compared to the other three parameters. Its proportional absolute error reaches a maximum value of $54.31 \%$ in plot $\mathrm{S} 1$ for sample size equal to 10 . A significant reduction in the committed error is obvious when the sample size increases from 10 to 30 trees.

The scale parameter $(b)$ of the Weibull function had smaller errors for all sample sizes compared to the location parameter $\left(\mu_{0}\right)$ of the Chaudhry-Ahmad function.

Finally, it should be noted that parameters " $b$ " and " $\mu_{0}$ " (that are related with the location of the distribution), had smaller errors compared to the " $a$ " and " $c$ " parameters that are responsible for the shape of the distribution.

\subsection{Set-2}

Large differences were observed in the average production among the set- 2 plots (table III). The lowest mean production was found in plot N36 $(1.33 \mathrm{~kg} / \mathrm{tree})$, and the highest in N6 (4.7 kg/tree). The within plot variance showed a clear increasing tendency for increasing average plot production (figure 4).

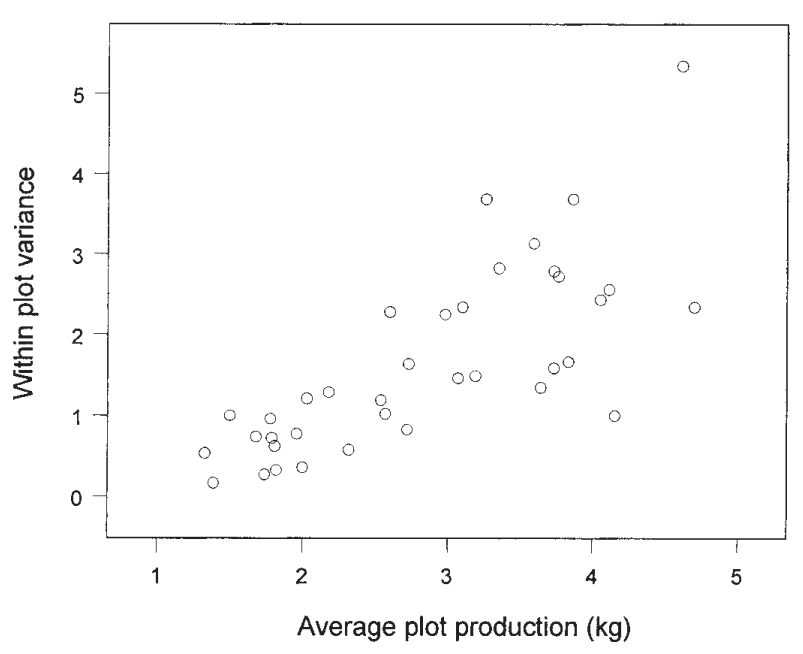

Figure 4. Mean plot production with respect to within plot variance.

Only seven distributions (18\%) are negatively skewed showing that in general the mean is bigger than the mode and the median of the distribution.

The parameter estimates are shown in table III. The scale parameter of the Weibull function and the location parameter of the Chaudhry-Ahmad function were found to be highly correlated with the mean production of each plot. A strong relationship exists between the scale parameter of the Weibull function and the average plot production $\left(R^{2}=0.99\right)$. The same relationship for the location parameter of the Chaudhry-Ahmad function is not so strong $\left(R^{2}=0.86\right)$ (figure $\left.5 a\right)$.

The shape parameters ( $c$ and $a \mu_{0}^{2}$ ) were less correlated with other measures of the actual distributions. The best correlation coefficients resulted between both the shape parameters and the within plot coefficient of variation $(C V)$. As shown in figure $5 b$, this relationship is a non-linear one for both parameters. Apparently, when the coefficient of variation of the actual distribution increases from 20 to $35 \%$, the shape parameter of the ChaudhryAhmad function reduces significantly; but, when the $C V$ reaches a value of $40 \%$ (standard deviation is four times bigger than the mean), then the reduction in " $a \mu_{0}{ }^{2}$ " becomes smaller.

The final step of the model comparison was to calculate the error index given in equation (5), for the set- 2 plots. The t-test for this index resulted in a non-significant difference between errors made by the two pdfs $(p=0.60)$. 
Table III. Descriptive statistics and parameter estimates for set-2 plots.

\begin{tabular}{|c|c|c|c|c|c|c|c|c|c|}
\hline \multirow[b]{3}{*}{ Plot } & \multicolumn{5}{|c|}{ Descriptive Statistics } & \multicolumn{4}{|c|}{ Maximum Likelihood Parameter Estimates } \\
\hline & \multirow[b]{2}{*}{ Min } & \multirow[b]{2}{*}{ Max } & \multirow[b]{2}{*}{ Mean } & \multirow[b]{2}{*}{ Sk } & \multirow[b]{2}{*}{ Kur } & \multicolumn{2}{|c|}{ WEIBULL } & \multicolumn{2}{|c|}{ CHAUDHRY \& AHMAD } \\
\hline & & & & & & $c$ & $b$ & $a$ & $\mu_{0}$ \\
\hline N1 & 0.73 & 4.85 & 3.07 & -0.46 & 0.20 & 2.71 & 3.30 & 0.07 & 1.85 \\
\hline N2 & 1.78 & 7.13 & 4.11 & 0.28 & 0.20 & 2.94 & 4.78 & 0.05 & 3.18 \\
\hline N3 & 1.30 & 3.80 & 2.32 & 0.63 & -0.03 & 3.64 & 2.64 & 0.26 & 2.06 \\
\hline N4 & 1.08 & 6.55 & 3.26 & 0.91 & -0.35 & 1.92 & 3.69 & 0.05 & 2.09 \\
\hline N5 & 2.35 & 5.58 & 4.15 & -0.43 & -0.61 & 3.88 & 4.34 & 0.12 & 3.75 \\
\hline N6 & 3.35 & 8.50 & 4.70 & 1.98 & 4.22 & 3.16 & 5.33 & 0.08 & 4.27 \\
\hline N7 & 1.30 & 6.70 & 3.86 & 0.34 & -1.04 & 2.29 & 4.36 & 0.04 & 2.55 \\
\hline N8 & 1.23 & 5.80 & 3.35 & 0.05 & -1.53 & 2.28 & 3.79 & 0.06 & 2.16 \\
\hline N9 & 2.17 & 6.88 & 4.61 & 0.10 & -0.90 & 3.05 & 5.25 & 0.06 & 3.83 \\
\hline N10 & 0.75 & 3.30 & 1.79 & 0.84 & -0.20 & 2.39 & 2.02 & 0.25 & 1.34 \\
\hline N11 & 2.23 & 6.03 & 3.64 & 0.87 & 0.64 & 3.20 & 3.93 & 0.12 & 3.21 \\
\hline N12 & 0.69 & 6.85 & 3.59 & 0.21 & 0.29 & 2.25 & 4.04 & 0.04 & 1.81 \\
\hline N13 & 2.18 & 6.00 & 3.83 & 0.35 & -0.80 & 2.96 & 4.24 & 0.09 & 3.27 \\
\hline N14 & 1.76 & 5.81 & 4.05 & -0.34 & -1.78 & 2.56 & 4.47 & 0.06 & 3.09 \\
\hline N15 & 1.28 & 7.13 & 3.76 & 0.48 & 1.17 & 2.56 & 4.25 & 0.05 & 2.61 \\
\hline N16 & 1.73 & 6.75 & 3.73 & 0.70 & -0.60 & 2.71 & 4.43 & 0.06 & 3.08 \\
\hline N17 & 0.95 & 5.50 & 2.98 & 0.25 & -0.49 & 2.29 & 3.37 & 0.07 & 1.90 \\
\hline N18 & 0.95 & 5.38 & 3.10 & 0.11 & -1.13 & 2.31 & 3.51 & 0.06 & 1.94 \\
\hline N19 & 0.98 & 2.85 & 2.00 & -0.41 & -0.27 & 4.13 & 2.20 & 0.34 & 1.68 \\
\hline N20 & 0.93 & 3.88 & 1.96 & 1.60 & 3.65 & 2.49 & 2.21 & 0.25 & 1.57 \\
\hline N21 & 1.03 & 4.70 & 2.57 & 0.52 & 1.79 & 2.85 & 2.88 & 0.13 & 1.93 \\
\hline $\mathrm{N} 22$ & 1.40 & 4.00 & 2.72 & -0.24 & -1.12 & 3.65 & 3.01 & 0.16 & 2.24 \\
\hline $\mathrm{N} 23$ & 1.03 & 5.43 & 2.60 & 1.27 & 0.47 & 1.96 & 2.95 & 0.09 & 1.83 \\
\hline $\mathrm{N} 24$ & 1.60 & 5.15 & 3.19 & 0.54 & -0.75 & 2.82 & 3.76 & 0.11 & 2.62 \\
\hline $\mathrm{N} 25$ & 2.03 & 5.40 & 3.73 & 0.04 & -1.58 & 2.78 & 4.18 & 0.09 & 3.13 \\
\hline N26 & 0.70 & 3.73 & 1.78 & 0.76 & 0.05 & 2.05 & 2.01 & 0.19 & 1.18 \\
\hline N27 & 1.15 & 4.90 & 2.73 & 0.39 & -1.22 & 2.44 & 3.09 & 0.10 & 1.98 \\
\hline N28 & 0.95 & 3.98 & 2.54 & 0.10 & -1.35 & 2.73 & 2.87 & 0.12 & 1.84 \\
\hline N29 & 0.63 & 3.68 & 1.81 & 1.39 & 3.62 & 2.50 & 2.03 & 0.25 & 1.34 \\
\hline N30 & 0.35 & 3.63 & 1.50 & 0.88 & 1.00 & 1.64 & 1.68 & 0.19 & 0.74 \\
\hline N31 & 0.68 & 3.60 & 1.68 & 1.08 & 1.93 & 2.18 & 1.90 & 0.23 & 1.16 \\
\hline N32 & 1.13 & 2.73 & 1.82 & 0.54 & -1.04 & 3.67 & 2.01 & 0.49 & 1.60 \\
\hline N33 & 0.53 & 2.23 & 1.74 & -1.50 & 2.70 & 4.54 & 1.90 & 0.30 & 1.25 \\
\hline N34 & 0.65 & 1.95 & 1.39 & -0.25 & -0.27 & 4.15 & 1.53 & 0.74 & 1.18 \\
\hline N35 & 0.58 & 3.53 & 2.03 & 0.10 & -1.46 & 2.06 & 2.29 & 0.13 & 1.16 \\
\hline N36 & 0.28 & 2.33 & 1.33 & 0.24 & -1.55 & 1.99 & 1.50 & 0.27 & 0.64 \\
\hline N37 & 0.53 & 3.93 & 2.18 & 0.03 & -0.99 & 2.15 & 2.46 & 0.11 & 1.19 \\
\hline
\end{tabular}

For symbol description see table I.

\section{DISCUSSION}

Large differences were found among the sampled plots with respect to their resin-yielding ability. Such differences could be attributed to edaphic, climatic or genetic factors [7]. The first two of these seem to be the most important in our case because the spatial distribution of the experimental plots does not advocate the existence of genetic differences among trees of different plots. Obviously, tapping should be restricted to the more pro- ductive stands (where extraction will be profitable), leaving the less favorable ones for timber production.

At present, no information concerning modelling resin production distributions exists. Frequency distributions presented by different authors are in accordance with the data presented in this paper [21]. Peters [16] reports that resin-yield distributions obtained by micro-chipping of slash pine trees, were strongly skewed to the high-yield side. We have observed that only 7 out of 40 distributions studied were negatively skewed. 
(a)

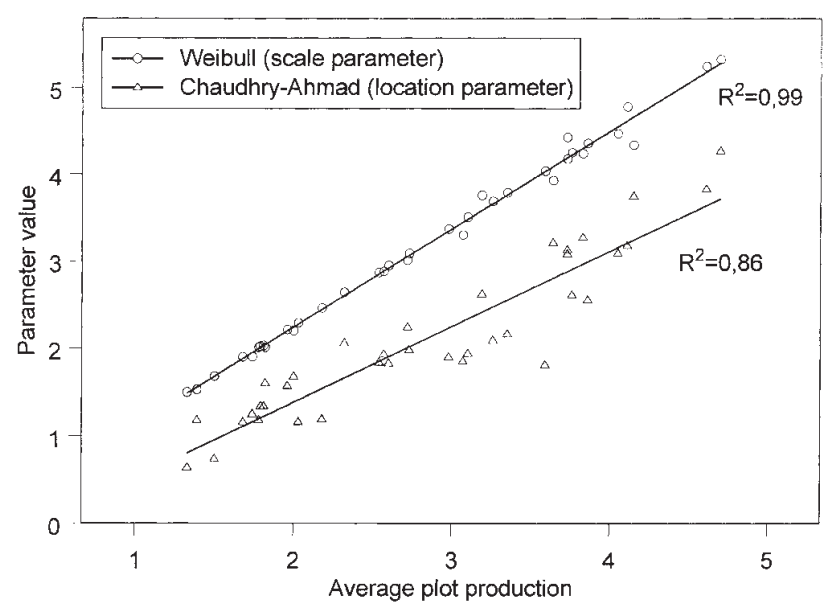

(b)

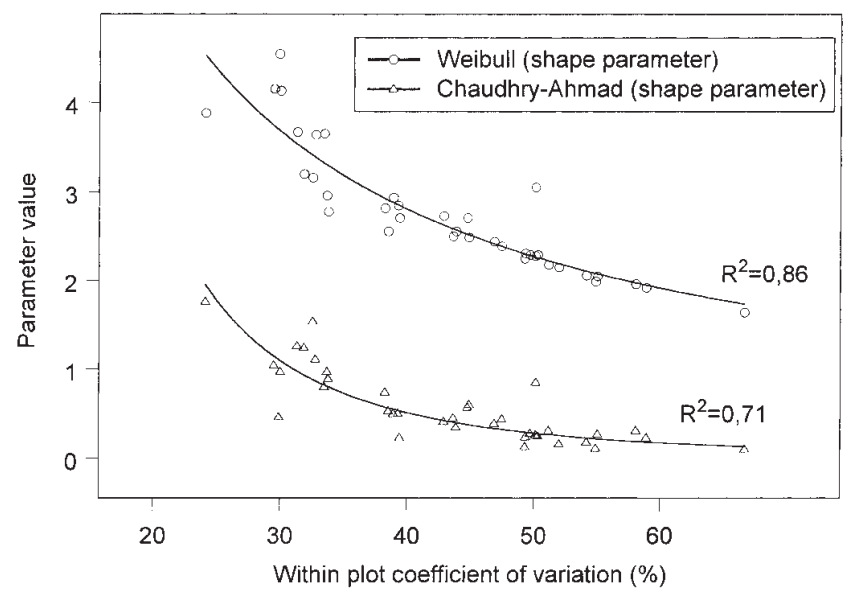

Figure 5. Regression models for the scale and location parameters (a) and for the shape parameters (b) of the probability functions.

Our results indicate that the Chaudhry-Ahmad and the Weibull function, when fitted by ML to the experimental plots gave equal estimation errors. Chaudhry and Ahmad [5] found that their function was better than the log-normal pdf in fitting data from diameters of even-aged stands of Douglas-fir. They used the $x^{2}$ statistic to compare the probability functions. In our opinion, the error index that we developed to compare the probability functions, is more suitable than the $x^{2}$ statistic, which has been also used by other authors [10]. The reason is that this statistic treats equally all deviations from the real frequencies, regardless of the economic importance of the errors. We preferred to weight the errors made by the models by giving greater weights to errors made at high production classes.

Results suggest that the use of 10-tree samples permits a good estimation of parameters of the Weibull function while bigger samples are necessary for the ChaudhryAhmad density function. Shiver [20] reports that using 50-tree sample plots, the Weibull function predicts diameter distributions with less than $10 \%$ error in any diameter class. Such sample sizes, although desirable, are not feasible in the case of resin-yield distributions due to the cost of data collection.

No major differences were detected between the Weibull and the Chaudhry-Ahmad functions. Nevertheless, the best model should be chosen at later stages of the modelling process, when parameters of both the probability functions will be regressed against other, easily measured stand attributes.
Apart from the location and scale parameters, which are known to be correlated with the mean of the distribution, the shape parameters were well correlated with the within plot coefficient of variation. Those results are in accordance with those obtained by Bondarev [4], who found that the shape parameter of the Weibull function was negatively correlated with the coefficient of age variation of pure larch stands. Especially the shape parameter of the Weibull function has been traditionally interpreted as the "skewness" parameter [2, 18], but in the case of resin-yield distributions it should not be regarded as such because the vast majority of the distributions are positively skewed. As we have shown, this parameter usually lies in the interval from 1 to 3.6 and rarely shows higher values. Inside this interval, the shape parameter is related to the dispersion of the distribution. The bigger the dispersion the smaller the shape parameter.

The proposed probability functions are useful for predicting the stand resin production. Models based on resinyield distributions should be preferred against models of the mean stand production because the formers provide information about the variance of the production.

On the other hand, models of resin-yield distributions can be useful for tree breeding purposes [17]. Tree breeders have observed that the resin production distribution is strongly skewed to the high yield classes [9, 16, 21], deviating significantly from the normal distribution. Nevertheless, the computation of the selection intensity for superior individuals has been based on the assumption of normality of the underlying distribution. Under this assumption the intensity of selection is underestimated. 
Acknowledgments: The authors whish to thank the Junta de Castilla y León for the technical support. We are also grateful to two anonymous referees, Nieves Cañadas, Santiago Gonzalez-Martinez, and to Irena T. Farrell for their comments on the manuscript. Special thanks to Jesus de Miguel for his help in preparing the figures and to Francisco Javier Auñon for his help in data collection. This work was founded by INIA, project SC97-118.

\section{REFERENCES}

[1] Allué C., Allué M., Notas sobre la marcha ordenada del monte "Pinar Viejo" (Coca, Segovia) I, in: Actas de la reunión de Valsain, SECF, Madrid, 1994, pp. 295-306.

[2] Bailey R.L., Dell T.R., Quantifying diameter distributions with the Weibull function, For. Sci. 19 (1973) 97-104.

[3] Baldwin V.C.Jr., Peterson K.D., Burkhart H.E., Amateis R.L., Dougherty P.M., Equations for estimating Loblolly pine branch and foliage weight and surface area distributions, Can. J. For. Res. 27 (1997) 918-927.

[4] Bondarev A., Age distribution patterns in open boreal Dahurican larch forests of Central Siberia, For. Ecol. Manage. 93 (1996) 205-214.

[5] Chaudhry M.A., Ahmad M., On a probability function useful in size modelling, Can. J. For. Res. 23 (1993) 1679-1683.

[6] De Groot P., Fleming R.A., Analysis and modelling of cohort life tables of Jack pine seed cones, Can. J. For. Res. 24 (1994) 1579-1592.

[7] Deshmukh D.K., Characterization of Chir pine (Pinus roxburghii Sargent) for resin yielding capacities, Indian Forester, June (1966) 368-390.

[8] Efron B., Bootstrap methods: another look at the jackknife, Ann. Statist. 7 (1979) 1-26.

[9] Goddard R.A., Peters W.J., Progress in the selection and breeding of superior trees to upgrade gum yield, Naval Stores Rev. 74 (1965) 4-5,13,15.
[10] Kershaw J.A., Maguire D.A., Crown structure in western hemlock, Douglas-fir and grand fir in western Washington: horizontal distribution of foliage within branches, Can. J. For. Res. 26 (1996) 128-142.

[11] Khatouri M., Dennis B., Growth-and-yield model for uneven-aged Cedrus atlantica stands in Morocco, For. Ecol. Manage. 36 (1990) 253-266.

[12] Kilkki P., Maltamo M., Mykkänen R., Päivinen R., Use of the Weibull function in estimating the basal area dbh-distribution, Silva Fenn. 23 (1989) 311-318.

[13] Maltamo M., Comparing basal area diameter distributions estimated by tree species and for the entire growing stock in a mixed stand, Silva Fenn. 31 (1997) 53-65.

[14] Maltamo M., Puumalainen J., Päivinen R., Comparison of beta and Weibull functions for modelling basal area diameter distributions in stands of Pinus sylvestris and Picea abies, Scand. J. For. Res. 10 (1995) 284-295.

[15] Mergen F., Inheritance of oleoresin yield in Slash pine, Naval Stores Rev. 64, 9 (1954) 8-20-9.

[16] Peters J.W., Variation in oleoresin yielding potential of selected Slash pines, For. Sci. 17 (1971) 306-307.

[17] Prada M.A., Allué M., Gil L., Pardos J.A., Programa de mejora genética de Pinus pinaster Ait grandes productores de miera en la provincia de Segovia, in: Actas de la reunión de Madrid, SECF, Madrid, (1996) pp. 67-71.

[18] Rennolls K., Geary D.N., Rollinson T.J.D., Characterizing diameter distributions by the use of the Weibull distribution, Forestry 58 (1985) 57-66.

[19] Reynolds M.R.Jr., Burk T., Huang W.C., Goodness-offit tests and model selection procedures for diameter distribution models, For. Sci. 34 (1988) 373-399.

[20] Shiver B.D., Sample sizes and estimation methods for the Weibull distribution for unthinned Slash pine plantation diameter distributions, For. Sci. 34 (1988) 809-814.

[21] Squillace A.E., Combining superior growth and timber quality with high gum yield in Slash pine, in: 8th South Conf. Forest Tree Impr. Proc. (1965) pp. 73-76. 